\title{
Ammonium availability in the Late Archean nitrogen cycle
}

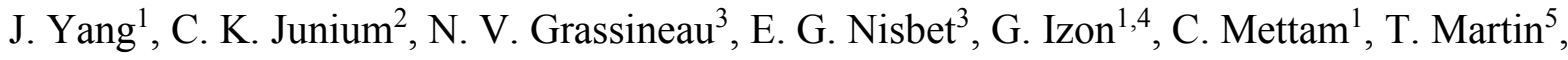
and A. L. Zerkle ${ }^{1}$

${ }^{1}$ School of Earth and Environmental Sciences and Centre for Exoplanet Science, University of St Andrews, St Andrews, Fife, KY16 9AL, Scotland, UK

${ }^{2}$ Department of Earth Sciences, Syracuse University, 322 Heroy Geology Laboratory, NY 13244, USA

${ }^{3}$ Department of Earth Sciences, Royal Holloway, University of London, Egham TW20 OEX, $U K$

${ }^{4}$ Current address: Department of Earth, Atmospheric \& Planetary Sciences, Massachusetts Institute of Technology, Cambridge, MA 02139, USA

${ }^{5} 6$ Autumn Close, Greendale, Harare, Zimbabwe 
The bioavailability of essential nutrients such as nitrogen (N) and phosphorus (P) has fluctuated with the chemical evolution of Earth surface environments over geologic timescales. However, significant uncertainty remains over the evolution of Earth's early nitrogen cycle, particularly how and when it responded to the evolution of oxygenic photosynthesis. Here we apply multi-proxy geochemical analyses (Fe speciation, $\delta^{13} \mathrm{C}$ and $\delta^{15} \mathrm{~N}$ ) to exceptionally well-preserved shales from the approximately 2.7 Ga Manjeri Formation in the Belingwe Greenstone Belt, Zimbabwe, to evaluate the redox status of Earth's early nitrogen cycle and decipher feedbacks associated with the initial stages of planetary oxygenation. These continental shelf sediments have previously been linked to early cyanobacterial oxygen production, and provide a direct test of conflicting hypotheses concerning the importance of nitrogen oxyanions in the Late Archean. Our data reveal a dominantly anaerobic marine nitrogen cycle, where ammonium-replete ferruginous waters underlay an ephemeral oxygen oasis. Driven by the emergence of oxygenic photosynthesis, increased primary productivity could have periodically strengthened export production, allowing for accumulation of ammonium in the water column during organic matter degradation. Restricted oxygen availability could have allowed upwelling ammonium to reach the photic zone, providing ample nitrogen to fuel a prolific Late Archean biosphere. 
The majority of organic- and mineral-bound nitrogen $(\mathrm{N})$ is initially derived from relatively inert atmospheric dinitrogen $\left(\mathrm{N}_{2}\right)$ gas. Early in Earth's history, abiotic $\mathrm{N}_{2}$ fixation reactions induced by lightning, photochemical processes, or catalytic reduction in hydrothermal systems could have provided nitrogen to the biosphere ${ }^{1}$. These sources of fixed nitrogen, however, were likely sensitive to the prevailing environmental conditions (e.g., $p \mathrm{CO}_{2}{ }^{2}$ ), restricting nitrogen bioavailability while effectively curtailing the expansion of the biosphere. Consequently, the biochemical innovation that allowed prokaryotes to reduce $\mathrm{N}_{2}$ (diazotrophy) would have provided unprecedented bioavailable nitrogen, removing the dependence on abiotic processes and opening previously unavailable ecological niches. Nitrogen isotope evidence suggests that iron-molybdenum (FeMo)-based diazotrophy had likely evolved by at least 3.2-billion-years-ago $(\mathrm{Ga})^{3,4}$, and has since served as the primary source of nitrogen to the marine environment. This new source of nitrogen could presumably have benefitted the biosphere through the degradation of diazotrophic biomass in the water column and in the sediments, allowing for the accumulation of ammonium $\left(\mathrm{NH}_{4}^{+}\right)$in the anoxic deep ocean. However, direct geochemical evidence for bioavailable $\mathrm{NH}_{4}{ }^{+}$is currently lacking.

In modern oxygenated oceans, the majority of ammonium is either rapidly recycled in the photic zone or sequentially oxidised to nitrite $\left(\mathrm{NO}_{2}{ }^{-}\right)$and nitrate $\left(\mathrm{NO}_{3}^{-}\right)$via nitrification, a process dependant on molecular oxygen $\left(\mathrm{O}_{2}\right)$. Ammonium, nitrite and nitrate can be assimilated directly, or returned to the atmosphere as $\mathrm{N}_{2}$ via chemolithotrophic processes that are generally confined to redox interfaces. Denitrification (the reduction of $\mathrm{NO}_{3}{ }^{-}$to $\mathrm{N}_{2}$ ) and anaerobic ammonium oxidation (anammox, the oxidation of $\mathrm{NH}_{4}{ }^{+}$to $\mathrm{N}_{2}$ with $\mathrm{NO}_{2}^{-}$) both occur under suboxic conditions in oxygen-minimum zones and in marine sediments ${ }^{5}$. These $\mathrm{N}$ loss processes are dependent on a supply of oxidised nitrogen species, and are therefore 
likely to have been limited prior to the rise of atmospheric $\mathrm{O}_{2}$ during the Great Oxidation Event at $\sim 2.3 \mathrm{Ga}^{6,7}$.

Many of the metabolisms within the nitrogen cycle are associated with a measurable nitrogen isotope fractionation, discriminating between ${ }^{15} \mathrm{~N}$ and ${ }^{14} \mathrm{~N}$, and preferentially enriching the reaction products in the lighter isotope. Given that many of these reactions are redox controlled, variability in the environmental redox state is reflected in the nitrogen isotopic composition (expressed as $\delta^{15} \mathrm{~N}=\left[\left({ }^{15} \mathrm{~N} /{ }^{14} \mathrm{~N}\right)_{\text {sample }} /\left({ }^{15} \mathrm{~N} /{ }^{14} \mathrm{~N}\right)\right.$ air -1$] \times 1000$, in \%o) of dissolved inorganic nitrogen (DIN). This $\delta^{15} \mathrm{~N}$ variability is communicated to the geological record through biological uptake and organic matter burial, presenting a window into the operation of the ancient nitrogen cycle through the $\delta^{15} \mathrm{~N}$ of sedimentary organic matter.

Diazotrophy yields a relatively small enzyme-specific isotope effect, with organisms exploiting the FeMo-bearing nitrogenase producing organic matter with $\delta^{15} \mathrm{~N}$ values ranging from -4 to $+2 \%{ }^{8}$. Alternative nitrogenases are associated with larger fractionations, resulting in biomass with $\delta^{15} \mathrm{~N}$ values as low as $-7 \%{ }^{9}$; however, environmental expression of these alternative nitrogenases appears to be confined to modern terrestrial environments and matforming salt marsh cyanobacteria ${ }^{10}$. Regardless of the complexities involved in discerning between the specific the nitrogenases, the FeMo-nitrogenase is thought to be the ancestral form, with alternative nitrogenases emerging much later ${ }^{3,11}$.

By contrast, nutrient assimilation is associated with much larger nitrogen isotope fractionations. For example, biological ammonium assimilation can produce fractionations in excess of $20 \%$, resulting in highly ${ }^{15} \mathrm{~N}$-depleted biomass. Critically, however, this isotope effect is only expressed when ammonium concentrations are high enough to prevent its complete utilisation $^{12}$ and thus is rarely seen in modern environments. The net impact of nitrification, denitrification and anammox serves to enrich the residual dissolved nitrogen species in ${ }^{15} \mathrm{~N}$ by as much as $10-25 \%{ }^{13,14}$. The high $\delta^{15} \mathrm{~N}$ of nitrate present in modern anoxic 
upwelling zones, for instance, is the result of progressive denitrification that is conveyed to sedimentary organic matter via biological nitrate assimilation ${ }^{15}$. Given that incomplete ammonium assimilation would require a dissolved ammonium reservoir in excess of biological need ${ }^{12}$, the $\delta^{15} \mathrm{~N}$ of modern marine organic matter largely reflects the isotopic composition of dissolved nitrate $(\sim 5 \%)^{13}$, which is dictated by the global balance between denitrification/anammox and diazotrophy.

Prior to the widespread establishment of oxygenic photosynthesis, the nitrogen cycle would have been much simpler, driven by the interplay between diazotrophy, ammonium regeneration and assimilation. The chemostratigraphic record of this primitive nitrogen cycle should vary around its input, and record $\delta^{15} \mathrm{~N}$ values lower than $0 \%$ when ammonium is replete and incompletely assimilated. The rise of atmospheric $\mathrm{O}_{2}$ during the Great Oxidation Event (GOE) at $\sim 2.3 \mathrm{Ga}^{7}$ and the subsequent partial oxygenation of the surface ocean is thought to have revolutionised the nitrogen cycle, stimulating widespread nitrification-denitrification. Such a profound change in the operation of the nitrogen cycle is evidenced by increased organic $\delta^{15} \mathrm{~N}$ values (to $>+5 \%$ ), reflecting the uptake of residual ${ }^{15} \mathrm{~N}$-enriched oxidized nitrogen species $^{6,16}$. Evidence for sustained aerobic nitrogen cycling prior to the Paleoproterozoic is lacking, with available datasets advocating only episodic oxidative $\mathrm{N}$-cycling ${ }^{17,18}$. Therefore, while localised aerobic nitrogen cycling may have emerged in the prelude to the GOE, nitrogen oxyanions seemingly remained a subordinate component of the nitrogen cycle until later in Earth history.

Here we investigate the nitrogen cycle and its response to localised oxygenation during the deposition of the $\sim 2.7$ Ga Manjeri Formation (Fm) from the Belingwe Greenstone Belt in Zimbabwe (Figure S1). The studied succession unconformably overlies an Archean gneissic terrain, deepening progressively through conglomerates and intertidal sands, carbonates, cherts and silts of the Spring Valley Member and subtidal Shavi Member, to the 
exceptionally well-preserved shales of the Jimmy Member. Lead-lead isochrons derived from Manjeri Fm stromatolitic limestones constrain its deposition to $2.706 \pm 0.049 \mathrm{Ga}^{19}$.

Sedimentary textures imply that the Jimmy Member was deposited in a deeper shelf setting below wave base ${ }^{20}$. The Manjeri Fm also hosts stromatolites and algal mat carbonates that have been interpreted as cyanobacterial ${ }^{21}$, providing direct macroscopic evidence for oxygen production. Overall, the metamorphic grade of the studied succession is remarkably low for rocks of this age, as supported by the preservation of texturally pristine and mineralogically

unaltered komatiites ${ }^{22}$. Maximum post-depositional temperatures have been estimated at 200$300^{\circ} \mathrm{C}$, though they are likely as low as $200^{\circ} \mathrm{C}$ in the specific study area ${ }^{21}$. Given available experiential and empirical constraints, the thermal regime of these rocks (lowermost greenschist) limits metamorphic alteration of the primary $\delta^{15} \mathrm{~N}$ signals to $1-3 \%$; these processes can also cause a divergence between kerogen and bulk rock $\delta^{15} \mathrm{~N}$ values of up to 3$4 \%{ }^{23}$. Detailed sample descriptions and further discussion of data fidelity are provided in the supplementary information (SI).

\section{Ocean chemistry during deposition of the Manjeri Fm}

The depositional redox conditions of the Manjeri Fm were assessed using the wellestablished iron $(\mathrm{Fe})$ speciation proxy ${ }^{24}$. Here, the ratio of highly reactive $\mathrm{Fe}$ to total $\mathrm{Fe}$ $\left(\mathrm{Fe}_{\mathrm{HR}} / \mathrm{Fe}_{\mathrm{T}}\right)$ can be used in well-preserved sedimentary rocks to determine the oxygen content of their depositional setting. In anoxic settings, the fraction of pyrite-housed highly reactive Fe serves as an additional proxy to discriminate between sulphide containing (euxinic) or ferruginous $\left(\mathrm{Fe}^{2+}\right.$-bearing) water columns. The Fe speciation data for the Spring Valley and Shavi Members imply persistently anoxic, ferruginous water column conditions $\left(\mathrm{Fe}_{\mathrm{HR}} / \mathrm{Fe}_{\mathrm{T}} \geq\right.$ $0.38, \mathrm{Fe}_{\mathrm{T}} / \mathrm{Al} \geq 0.5$, and $\left.\mathrm{Fe}_{\mathrm{Py}} / \mathrm{Fe}_{\mathrm{HR}}<0.7\right)$ with very limited redox variation over the course of their deposition (Fig. 1). The depositional environment of the Jimmy Member, however, was much more variable, with many $\mathrm{Fe}_{\mathrm{HR}} / \mathrm{Fe}_{\mathrm{T}}$ ratios falling between 0.22 and 0.38 , which 
preclude unambiguous interpretation. These aside, the Jimmy Member also exhibits evidence of deposition beneath a ferruginous water column $\left(\mathrm{Fe}_{\mathrm{HR}} / \mathrm{Fe}_{\mathrm{T}}>0.38\right)$, while some samples record lower $\mathrm{Fe}_{\mathrm{T}} / \mathrm{Al}(<0.5)$ and $\mathrm{Fe}_{\mathrm{HR}} / \mathrm{Fe}_{\mathrm{T}}(\leq 0.22)$ ratios consistent with oxic deposition (Fig. 1). These data suggest that the Jimmy Member could have been deposited in proximity to a chemocline separating ferruginous deep waters from an overlying mildly oxygenated watermass, as has been suggested for the Mesoarchaean oceans ${ }^{25}$. The simplest explanation for the presence of these intermittently oxic conditions is via in situ $\mathrm{O}_{2}$ production by oxygenic photosynthesis in a so-called "oxygen oasis", a hypothesis consistent with the presence of stromatolites in the shallow-water Manjeri $\mathrm{Fm}^{21}$. Supporting this inference, organic carbon isotope values $\left(\delta^{13} \mathrm{C}_{\text {org }}\right.$ ) range from $-36 \%$ to $-26 \%$ (Fig. 1), also consistent with carbon fixation dominated by photoautotrophy.

Trends in the pyrite-derived sulfur isotope data $\left(\delta^{34} \mathrm{~S}\right)$, and their relationship with total organic carbon content, provide further support for well-developed redox stratification (Fig. 1). The $\delta^{34} \mathrm{~S}$ values throughout the Spring Valley Member show little variation, averaging 4.6 $\pm 2.4 \%$ o $(1 \sigma)$, consistent with the small fractionations that accompany microbial sulfate reduction (MSR) under low sulfate concentrations ${ }^{26}$. By contrast, the Shavi Member features higher total organic carbon (TOC, mean of $0.7 \pm 0.5 \%)$ and lower $\delta^{34} \mathrm{~S}$ values $(-0.1 \pm 3.1 \%$ ), including an excursion to $\sim-10 \%$ coincident with an increase in TOC. These chemostratigraphic trends could represent more complete expression of MSR-derived sulfur isotope fractionations under more locally sulfate replete conditions. The Jimmy Member exhibits some larger $\delta^{34}$ S excursions (from $\sim+6 \%$ to $-20 \%$ ) independent of TOC, consistent with previous work on the Jimmy Member that documented large microscopic $\delta^{34} \mathrm{~S}$ variability, which requires an active microbial consortium featuring aerobic sulfur cycling ${ }^{20}$. As above, the $\delta^{34} \mathrm{~S}$ data support dynamic redox conditions with intermittent free $\mathrm{O}_{2}$ in a shallow oxygen oasis, where local sulphate availability and primary productivity were 
probably modulated by small-scale redox variations. Notably, although these data are consistent with the development of localized oxygenation during deposition of the Jimmy Member, the lack of evidence for water column euxinia throughout the succession supports previous suggestions that atmospheric oxygen levels remained too low to stimulate widespread pyrite oxidation, which would have provided a significant flux of sulphate to the oceans $^{27}$.

\section{Nitrogen cycling on a ferruginous continental shelf}

The $\delta^{15} \mathrm{~N}$ values of extracted kerogen $\left(\delta^{15} \mathrm{~N}_{\text {org }}\right)$ and bulk rock powders $\left(\delta^{15} \mathrm{~N}_{\text {bulk }}\right)$ are mostly below $0 \%$, with values ranging from $-11 \%$ to $+4 \%$ (Fig. 1). These light $\delta^{15} \mathrm{~N}$ values are most consistent with $\mathrm{N}_{2}$ fixation and incomplete ammonium assimilation, which would require locally non-limiting ammonium concentrations. Conservatively incorporating experimentally determined isotope fractionation factors associated with ammonium uptake $(\varepsilon \text { of }-4,-14,-27)^{12}$ within a closed system Rayleigh model reveals the potential $\delta^{15} \mathrm{~N}$-tajectory of the marine ammonium pool during progressive ammonia assimiliation (Fig. 2A). This model illustrates that the measured $\delta^{15} \mathrm{~N}$ values (Fig. 1) are consistent with $70-90 \%$ of the total ammonium pool having been assimilated into biomass (Fig. 2A). A corollary to this is that the long-term consumption and burial of ${ }^{15} \mathrm{~N}$-depleted ammonium would elevate the $\delta^{15} \mathrm{~N}$ of the residual ammonium pool toward extremely enriched values $\left(>50 \%{ }^{18}\right)$. We see no evidence of such high $\delta^{15} \mathrm{~N}$ values in our dataset, indicating that either ammonium assimilation never proceeded to completion, or that any ${ }^{15} \mathrm{~N}$-enriched ammonium was spatially separated from the shelf environment. Intriguingly, however, age-equivalent strata show very high $\delta^{15} \mathrm{~N}$ values (Fig. 2B), reaching values greater than $40 \%$ in the $\sim 2.7$ Ga Tumbiana Formation in Western Australia $^{28,29}$. These values have been variably interpreted as representing incomplete ammonium oxidation coupled to methane cycling ${ }^{28}$ or to ammonium volatilisation from alkaline lakes ${ }^{29}$. Assimilation of residual ${ }^{15} \mathrm{~N}$-enriched ammonium advected into an 
intracratonic basin could provide an additional explanation for the extremely high $\delta^{15} \mathrm{~N}$ values that typify this time period.

The $\delta^{15} \mathrm{~N}$ values (-9.5\% to $+1 \%$ ) of the Spring Valley and Shavi Members (Fig. 1) all indicate an anaerobic nitrogen cycle driven by biological $\mathrm{N}_{2}$ fixation and varying degrees of ammonium assimilation. Although an incursion of oxygenated waters is indicated by Fe speciation and $\delta^{34} \mathrm{~S}$ data from the Jimmy Member, only one sample exhibits mildly positive $\delta^{15} \mathrm{~N}(+4 \%)$ that is outside the range of values produced during $\mathrm{N}_{2}$ fixation $(-4 \%$ to $+2 \%$ ). Alternatively, this maxima in $\delta^{15} \mathrm{~N}$ could result from the progressive drawdown of the ammonium reservoir and ${ }^{15} \mathrm{~N}$-enrichment, due to either decreased supply or enhanced consumption in response to increased primary productivity. Regardless of the exact mechanism, these $\delta^{15} \mathrm{~N}$ data suggest that nitrification was not yet common enough for nitrate to serve as a significant source of nutrient $\mathrm{N}$, or that any nitrate that was formed was rapidly returned to the atmosphere via complete denitrification. This scenario implies that widespread nitrification was delayed by abundant reductants such as ferrous Fe, that presumably served as the primary sink for photosynthetic $\mathrm{O}_{2}$ in the largely-ferruginous shallow waters during this time (Fig. 1).

\section{Implications for nutrient cycling in the Late Archean}

Our results provide the first direct evidence for a large pool of bioavailable nitrogen that could have fuelled a Late Archean biosphere. Enhanced organic carbon export and subsequent release of ammonium would follow from higher rates of primary production associated with the rise of oxygenic photosynthesis. The largely anoxic deep oceans of the mid-to late-Archean could have allowed ammonium to accumulate, while biospheric nitrogen loss resulting from denitrification and anammox would have been restricted. Additionally, the advent of oxygenic photosynthesis would have allowed for photophosphorylation of ATP and increased energetic yields, which may have further promoted surface water $\mathrm{N}_{2}$ fixation. Such marine conditions were likely unique to the late Archean, following the proliferation of 
oxygenic photosynthesis, but prior to widespread oxygenation of the surface oceans when a stabilised aerobic nitrogen cycle developed ${ }^{6}$.

Given the $\sim 400$ million-year time lag between the deposition of the Manjeri Fm and the accumulation of atmospheric oxygen ${ }^{7}$, some other nutrient(s) must have prevented a nitrogen-induced positive feedback from creating a runaway biosphere and a cascade of oxidants to the Earth system. Under widespread iron-rich ocean conditions, the formation of iron-oxides at the chemocline may have enhanced phosphorus scavenging, or even promoted direct precipitation as vivianite, restricting dissolved phosphorous availability ${ }^{30}$. Therefore, marine phosphorus delivery and drawdown in shallow ferruginous oceans must have been critical in limiting the expansion of early life ${ }^{31}$.

\section{References}

1 Galloway, J. N. in Treatise on Geochemistry Vol. $10 \quad 475-498$ (2014).

2 Navarro-Gonzalez, R., McKay, C. P. \& Mvondo, D. N. A possible nitrogen crisis for Archaean life due to reduced nitrogen fixation by lightning. Nature 412, 61-64 (2001).

3 Stüeken, E. E., Buick, R., Guy, B. \& Koehler, M. C. Isotopic evidence for biological nitrogen fixation by Mo-nitrogenase from 3.2 Gyr. Nature 520, 666-669 (2015a).

4 Weiss, M. C. et al. The physiology and habitat of the last universal common ancestor. Nature Microbiology 1, 16116 (2016).

5 Dalsgaard, T., Thamdrup, B., Farias, L. \& Revsbech, N. P. Anammox and denitrification in the oxygen minimum zone of the eastern South Pacific. Limnology and Oceanography 57, 1331-1346 (2012).

6 Zerkle, A. L. et al. Onset of the aerobic nitrogen cycle during the Great Oxidation Event. Nature 542, 465-467 (2017). 
7 Luo, G. et al. Rapid oxygenation of Earth's atmosphere 2.33 billion years ago. Science Advances 2, 1-9 (2016).

8 Baursachs, T. et al. Nitrogen isotopic fractionation associated with growth on dinitrogen gas and nitrate by cyanobacteria. Limnology and Oceanography 54, 1403$1411(2009)$.

9 Zhang, X., Sigman, D. M., Morel, F. M. M. \& Kraepiel, A. M. L. Nitrogen isotope fractionation by alternative nitrogenases and past ocean anoxia. Proceedings of the National Academy of Sciences of the United States of America 111, 4782-4787 (2014).

10 Zhang, X. et al. Alternative nitrogenase activity in the environment and nitrogen cycle implications. Biogeochemistry 127, 189-198 (2016).

11 Boyd, E. S. \& Peters, J. W. New insights into the evolutionary history of biological nitrogen fixation. Frontiers in Microbiology 4, 201 (2013).

12 Hoch, M. P., Fogel, M. L. \& Kirchman, D. L. Isotope fractionation associated with ammonium uptake by a marine bacterium. Limnology and Oceanography 37, 14471459 (1992).

13 Sigman, D. M., Karsh, K. L. \& Casciotti, K. L. in Encyclopedia of Ocean Sciences (eds J. H. Steele, S. A. Thorpe, \& K. K. Turekian) 40-54 (Academic Press, 2009).

14 Brunner, B. et al. Nitrogen isotope effects induced by anammox bacteria. Proceedings of the National Academy of Sciences 110, 18994-18999 (2013).

15 De Pol-Holz, R., Robinson, R. S., Hebbeln, D., Sigman, D. M. \& Ulloa, O. Controls on sedimentary nitrogen isotopes along the Chile margin. Deep-Sea Research Part IiTopical Studies in Oceanography 56, 1100-1112, doi:10.1016/j.dsr2.2008.09.014 (2009). 
16 Kipp, M. A., Stüeken, E. E., Yun, M., Bekker, A. \& Buick, R. Pervasive aerobic nitrogen cycling in the surface ocean across the Paleoproterozoic Era. Earth and Planetary Science Letters 500, 117-126 (2018).

17 Garvin, J., Buick, R., Anbar, A. D., Arnold, G. L. \& Kaufman, A. J. Isotopic evidence for an aerobic nitrogen cycle in the latest Archean. Science 323, 1045-1048 (2009).

18 Godfrey, L. V. \& Falkowski, P. G. The cycling and redox state of nitrogen in the Archaean ocean. Nature Geoscience, doi:DOI: 10.1038/NGEO633 (2009).

19 Bolhar, R., Hofmann, A., Woodhead, J., Hergt, J. \& Dirks, P. Pb- and Nd-isotope systematics of stromatolitic limestones from the 2.7 Ga Ngezi Group of the Belingwe Greenstone Belt: constraints on timing of deposition and provenance. Precambrian Research 114, 277-294, doi:10.1016/s0301-9268(01)00229-7 (2002).

20 Grassineau, N. V., Abell, P., Appel, P. W. U., Lowry, D. \& Nisbet, E. G. Early life signatures in sulfur and carbon isotopes from Isua, Barberton, Wabigoon (Steep Rock) and Belingwe Greenstone Belts (3.8 to 2.7 Ga). Geological Society of America Memoirs 198, 33-52 (2006).

21 Abell, P. I., McClory, J., Martin, A. \& Nisbet, E. G. Archean stromatolites from the Ngesi Group, Belingwe Greenstone Belt, Zimbabwe - Preservation and stable isotopes - Preliminary Results. Precambrian Research 27, 357-383, doi:10.1016/03019268(85)90094-4 (1985).

22 Nisbet, E. G. et al. Uniquely fresh 2.7 Ga komatiites from the Belingwe greenstone belt, Zimbabwe. Geology 15, 1147-1150 (1987).

23 Stüeken, E. E., Zaloumis, J., Meixnerova, J. \& Buick, R. Differential metamorphic effects on nitrogen isotopes in kerogen extracts and bulk rocks. Geochimica et Cosmochimica Acta 217, 80-94 (2017). 
24 Poulton, S. W. \& Canfield, D. E. Development of a sequential extraction procedure for iron: implications for iron partitioning in continentally derived particulates. Chemical Geology 214, 209-221 (2005).

25 Eickmann, B. et al. Isotopic evidence for oxygenated Mesoarchean shallow oceans. Nature Geoscience (2018).

26 Habicht, K. S. \& Canfield, D. E. Sulfur isotope fractionation during bacterial sulfate reduction in organic-rich sediments. Geochimica et Cosmochimica Acta 61, 53515361 (1997).

27 Thomazo, C., Grassineau, N. V., Nisbet, E. G., Peters, M. \& Strauss, H. Multiple sulfur and carbon isotope composition of sediments from the Belingwe Greenstone Belt (Zimbabwe): A biogenic methane regulation on mass independent fractionation of sulfur during the Neoarchean? Geochimica et Cosmochimica Acta 121, 120-138 (2013).

28 Thomazo, C., Ader, M. \& Philippot, P. Extreme 15N-enrichments in 2.72-Gyr-old sediments: evidence for a turning point in the nitrogen cycle. Geobiology 9, 107-120 (2011).

29 Stüeken, E. E., Buick, R. \& Schauer, A. J. Nitrogen isotope evidence for alkaline lakes on late Archean continents. Earth and Planetary Science Letters 411, 1-10 (2015).

30 Derry, L. A. Causes and consequences of mid-Proterozoic anoxia. Geophysical Research Letters 42, 8538-8546 (2015).

31 Reinhard, C. T. et al. The evolution of the global phosphorus cycle. Nature 467, 1088-1090 (2016).

\section{Corresponding author information}


Correspondence and requests for materials should be addressed to Aubrey L. Zerkle, at az29@st-andrews.ac.uk

\section{Acknowledgements}

This study was supported financially by Natural Environment Research Council Standard Grants NE/M001156/1 (to ALZ, EN, and NG) and NE/J023485/2 (to ALZ), and National Science Foundation NSF EAR-1455258 (to CKJ). GI acknowledges continued support from the Simons Foundation (SCOL:290361) during final drafts of the manuscript. The authors thank M. Hunter for help in logging the NERCMAR core, D. Herd for assistance with petrography, A. Calder for assistance with XRF analyses, and A. Prave for thoughtprovoking discussion on Manjeri Fm strata. We also thank T. Laakso, C. Thomazo and M. Ader for constructive reviews that greatly improved the manuscript.

\section{Author contributions}

ALZ and EN conceived the study; JY, NG, EN, and TM collected the samples; JY, CKJ, NG, GI and CM processed samples and performed geochemical analyses; JY, ALZ and CKJ interpreted the data and wrote the manuscript with input from all co-authors.

\section{Declaration of competing interests}

The authors declare no competing financial interests.

\section{Figure Captions}

Figure 1. Lithological and geochemical data from the 2.7 Ga Manjeri Formation. Data include Fe speciation, the $\delta^{34} \mathrm{~S}$ of pyrite (\%o), total organic carbon (TOC; wt $\left.\%\right), \delta^{13} \mathrm{C}_{\text {org }}(\%)$, $\delta^{15} \mathrm{~N}_{\text {org }}(\%)$ and $\delta^{15} \mathrm{~N}_{\text {bulk }}(\%)$. For all data, uncertainties are smaller than the symbols. The blue and green shading in the $\mathrm{Fe}_{\mathrm{HR}} / \mathrm{Fe}_{\mathrm{T}}$ panel discriminates between oxic and anoxic depositional conditions, whereas the red and purple shading in the $\mathrm{Fe}_{\mathrm{Py}} / \mathrm{Fe}_{\mathrm{HR}}$ panel separates ferruginous and euxinic depositional conditions, respectively. The $\mathrm{Fe}_{\mathrm{Py}} / \mathrm{Fe}_{\mathrm{HR}}$ data are only plotted for samples where the corresponding $\mathrm{Fe}_{\mathrm{HR}} / \mathrm{Fe}_{\mathrm{T}}$ ratio exceeds 0.22 , suggesting anoxic 
depositional conditions. Red diamonds and purple crosses in the $\delta^{15} \mathrm{~N}$ panel differentiates between $\delta^{15} \mathrm{~N}_{\text {org }}$ and $\delta^{15} \mathrm{~N}_{\text {bulk, }}$, respectively.

Figure 2. Modeled $\delta^{15} \mathrm{~N}$ values that can reproduce temporal trends in the rock record. A. Rayleigh model illustrating the evolution of $\delta^{15} \mathrm{~N}$ values in biomass and the residual ammonium pool following non-quantitative uptake (based on experiments of Hoch et al. ${ }^{12}$; see SI for full model description). B. Temporal changes in $\delta^{15} \mathrm{~N}$ preserved in sediments over geologic time (updated from Zerkle et al. ${ }^{6}$ and Kipp et al. ${ }^{16}$ with references therein). Uncertainties are smaller than the symbols. Red diamonds and purple crosses illustrate $\delta^{15} \mathrm{~N}_{\text {org }}$ and $\delta^{15} \mathrm{~N}_{\text {bulk }}$ data from our study, as in Fig. 1. 


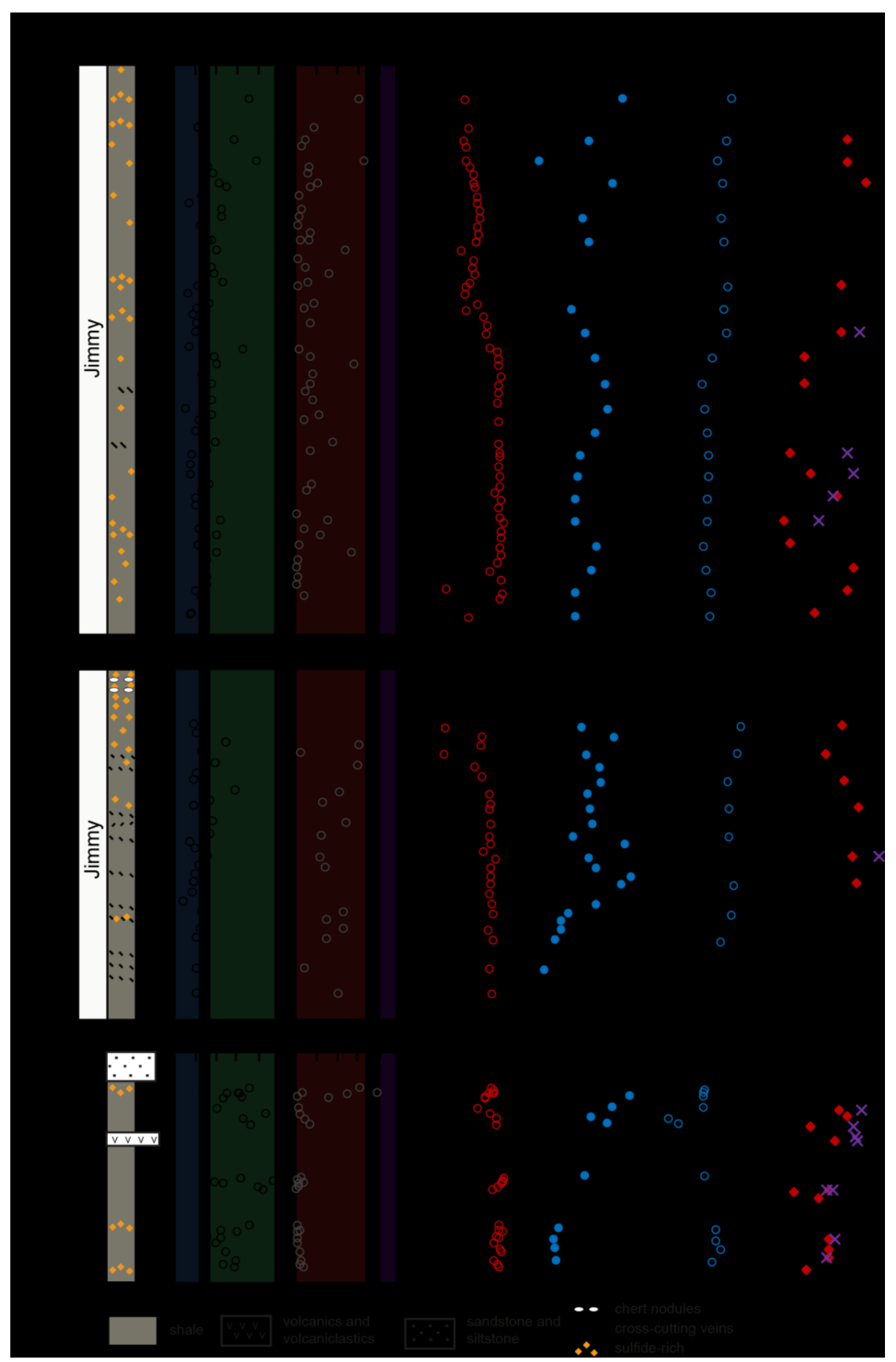

Figure 1. Lithological and geochemical data from the 2.7 Ga Manjeri Formation. Data were obtained from three cores, core NERMAR through the Spring Valley and Shavi members, and Cores A and B through the Jimmy member, which are plotted in ascending order (bottom to top). Data include Fe speciation, the $\delta^{34} \mathrm{~S}$ of pyrite (\%o), total organic carbon (TOC; wt $\%), \delta^{13} \mathrm{C}_{\text {org }}(\%), \delta^{15} \mathrm{~N}_{\text {org }}(\% \mathrm{o})$ and $\delta^{15} \mathrm{~N}_{\text {bulk }}(\%)$. For all data, uncertainties are smaller than the symbols. The blue and green shading in the $\mathrm{Fe}_{\mathrm{HR}} / \mathrm{Fe}_{\mathrm{T}}$ panel discriminates between oxic and anoxic depositional conditions, whereas the red and purple shading in the $\mathrm{Fe}_{\mathrm{Py}} / \mathrm{Fe}_{\mathrm{HR}}$ panel separates ferruginous and euxinic depositional conditions, respectively. The $\mathrm{Fe}_{\mathrm{Py}} / \mathrm{Fe}_{\mathrm{HR}}$ data are only plotted for samples where the corresponding $\mathrm{Fe}_{\mathrm{HR}} / \mathrm{Fe}_{\mathrm{T}}$ ratio exceeds 0.22 , suggesting anoxic depositional conditions. Red diamonds and purple crosses in the $\delta^{15} \mathrm{~N}$ panel differentiates between $\delta^{15} \mathrm{~N}_{\text {org }}$ and $\delta^{15} \mathrm{~N}_{\text {bulk, }}$, respectively. SV is the Spring Valley Member. 

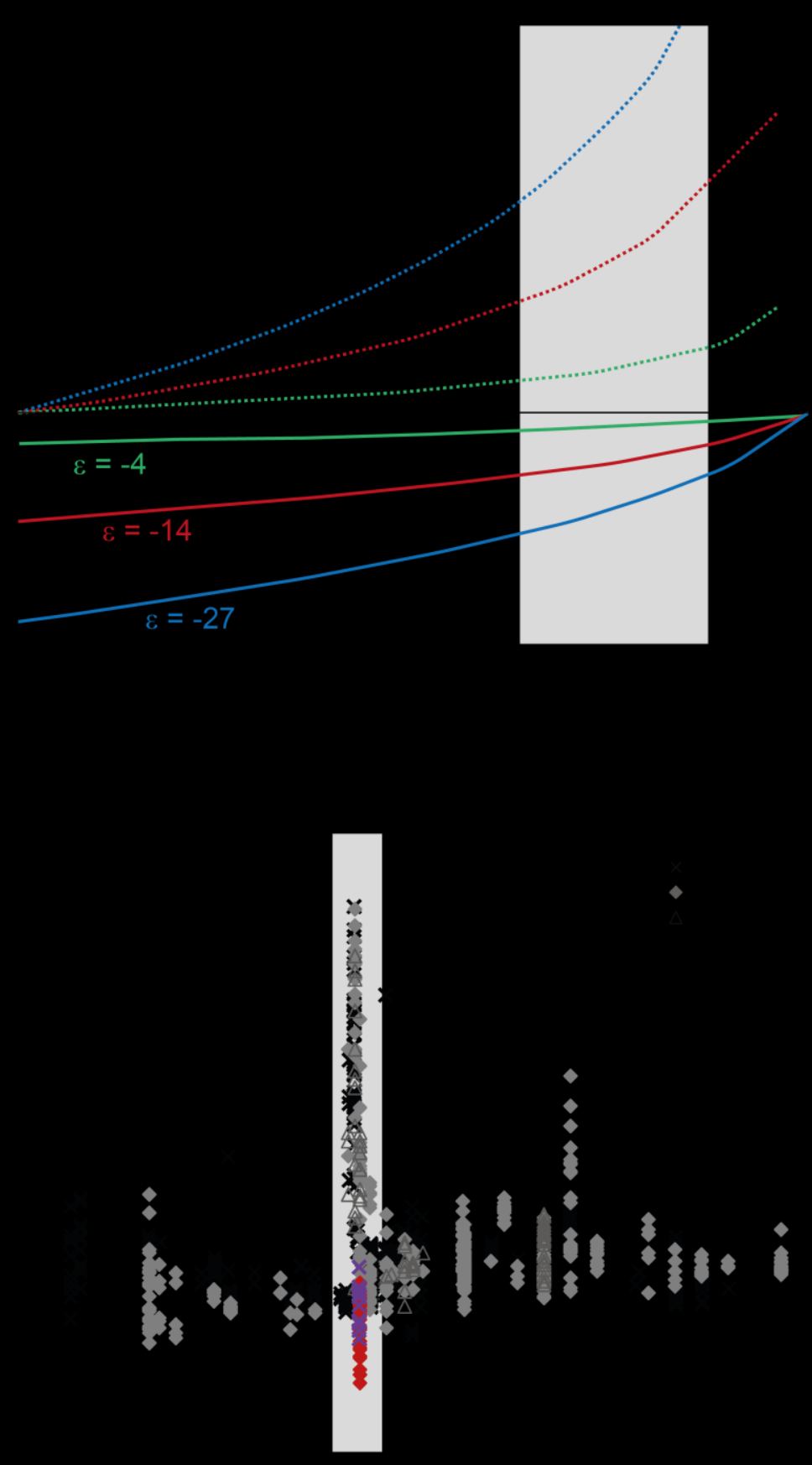

Figure 2. Modeled $\delta^{15} \mathrm{~N}$ values that can reproduce temporal trends in the rock record. A. Rayleigh model illustrating the evolution of $\delta^{15} \mathrm{~N}$ values in biomass and the residual ammonium pool following non-quantitative uptake (based on experiments of Hoch et al. ${ }^{18}$; see SI for full model description). B. Temporal changes in $\delta^{15} \mathrm{~N}$ preserved in sediments over geologic time (updated from Zerkle et al. ${ }^{5}$ and Kipp et al. ${ }^{22}$ with references therein). Uncertainties are smaller than the symbols. Red diamonds and purple crosses illustrate $\delta^{15} \mathrm{~N}_{\text {org }}$ and $\delta^{15} \mathrm{~N}_{\text {bulk }}$ data from our study, as in Fig. 1. 


\section{Online Methods}

\section{Iron Speciation and $\delta^{34} \mathbf{S}$ Analyses}

Oxic Fe extractions were performed at the University of St Andrews following the protocol developed by Poulton and Canfield ${ }^{24}$. Briefly, carbonate iron $\left(\mathrm{Fe}_{\mathrm{Carb}}\right)$ was extracted with a solution of sodium acetate at $\mathrm{pH} 4.5$ at $50^{\circ} \mathrm{C}$ for 48 hours; iron oxide (Feox) was extracted with a solution of sodium dithionite, tri-sodium citrate and acetic acid for 2 hours; magnetite iron $\left(\mathrm{Fe}_{\mathrm{Mag}}\right)$ was extracted with a solution of ammonium oxalate and oxalic acid for 8 hours; and poorly reactive sheet silicates (FepRs) were extracted by vigorous boiling for 1 minute in $12 \mathrm{~N} \mathrm{HCl}$. Iron contents of the sequential extracts were determined using a Thermo Scientific iCAP 6300 inductively coupled plasma optical emission spectrometer (ICP-OES) via external, matrix matched calibration (as described in Izon et al. ${ }^{32}$ ). Synthetic, matrix matched, 1 ppm Fe standards ( $\mathrm{n}>5$ in each run) reproduced better than $2 \%(1 \sigma$ relative standard deviation; RSD); replicate extractions of a PACS-2 sediment standard $(\mathrm{n}=5)$ reproduced better than $6 \%(1 \sigma \mathrm{RSD})$ for all Fe pools. In addition, full procedural duplicates of a selection of samples give an external reproducibility of $<0.05 \%$ for all extraction steps.

Pyrite-derived $\mathrm{Fe}\left(\mathrm{Fe}_{\mathrm{Py}}\right)$ was calculated gravimetrically from silver sulphide $\left(\mathrm{Ag}_{2} \mathrm{~S}\right)$ precipitated following a sequential $6 \mathrm{M} \mathrm{HCl}$ distillation to determine acid volatile sulphide ( $\left.\mathrm{Fe}_{\mathrm{AvS}}\right)$ and a hot chromous chloride distillation to determine chromous reducible sulphide $\left(\mathrm{Fe}_{\mathrm{CRS}}\right)$, such that $\mathrm{Fe}_{\mathrm{Py}}$ is the summation of the AVS and CRS phases ${ }^{33}$. Experimental triplicates for this distillation process at St Andrews demonstrate a $1 \sigma$ RSD better than $5 \%{ }^{34}$.

Major elemental abundances and total $\mathrm{Fe}\left(\mathrm{Fe}_{\mathrm{T}}\right)$ content were determined by X-ray fluorescence (XRF) at the University of St Andrews. The samples were fused using a mixed lithium tetraborate $\left(\mathrm{Li}_{2} \mathrm{~B}_{4} \mathrm{O}_{7} ; 20 \%\right)$ and lithium metaborate $\left(\mathrm{LiBO}_{2} ; 80 \%\right)$ flux, using ammonium iodide $\left(\mathrm{NH}_{4} \mathrm{I}\right)$ as a releasing agent. Fused samples were analysed on a Spectro Xepos HE instrument, utilising a 50 Watt end-window X-ray tube to excite the samples, and a 
$30 \mathrm{~mm}^{2}$ Peltier cooled Si-drift detector, providing spectral resolution $(\mathrm{FWHM}) \leq 155 \mathrm{eV}$ at $\mathrm{Mn}$ K-alpha. Reproducibility of Fe measurements was assessed by experimental comparison with Penryhn slate, where a value of $8.95 \pm 0.0 \%(3 \sigma, n=20)$ was obtained against a certified value of $8.94 \%$, with a limit of detection of $0.012 \%$. Other elemental oxides were similarly reproducible. All samples had greater than $0.5 \mathrm{wt} \% \mathrm{Fe}$, indicating that the Fe speciation method should robustly reflect depositional conditions ${ }^{35}$. In addition, samples from cores A and B had very low carbonate contents $(2-8 \%)$, and while carbonate contents are admittedly higher in the NERCMAR core (4-30\%, mean of 17\%), they are still low enough to confidently preclude significant dilution by diagenetic carbonate formation ${ }^{36}$.

Sulphur isotope $\left(\delta^{34} \mathrm{~S}\right)$ analyses were performed on the silver sulphide $\left(\mathrm{Ag}_{2} \mathrm{~S}\right)$ precipitated during the $\mathrm{CrCl}_{2}\left(\mathrm{Fe}_{\mathrm{Py}}\right)$ distillation by Iso-Analytical Laboratories, Cheshire, $\mathrm{UK}$ using standard EA-IRMS techniques. Data accuracy was assessed using reference materials IA-R061 with reproducibility of $0.11 \%$ o $(1 \sigma ; \mathrm{n}=10)$, and IAEA-SO-5 with reproducibility of $0.2 \%$ o $(1 \sigma ; \mathrm{n}=10)$. We have conservatively adopted the larger of these uncertainties to represent the precision of the resulting analyses.

\section{Carbon and Nitrogen analyses}

Total organic carbon (TOC) was measured at RHUL. Depending on their organic content, between 1 and $20 \mathrm{mg}$ of sample was decarbonated. Each sample was prepared following the protocol outlined by Grassineau ${ }^{37}$. Briefly, the samples were cleaned using highgrade methanol in an ultrasonic bath, then the carbonate fraction was removed at $100^{\circ} \mathrm{C}$ with a $20 \% \mathrm{HCl}$ leach. Finally, the samples were rinsed in triplicate with ultra-pure water and dried for analysis. Encapsulated in tin, analysis was conducted using a Fisons 1500 Series 2

elemental analyser ${ }^{18}$. At the start of each daily run, various carbon-bearing in-house and international standards (graphite, calcite, soils) were measured to calibrate the instrument. Instrumental drift was monitored via replicate analysis of a graphite standard. Instrumental 
blanks, in a form of empty crimped tin capsules, were also analysed regularly to flush the system and determine the instrumental background. Data have been both blank and drift corrected. Replicate analyses of samples and standards were better than $0.05 \%$.

Analyses of bulk nitrogen isotope ratios $\left(\delta^{15} \mathrm{~N}_{\text {bulk }}\right)$ and organic carbon isotope ratios $\left(\delta^{13} \mathrm{C}_{\text {org }}\right)$ were performed on rock powders decarbonated at St Andrews. We specifically avoided samples that showed visual evidence of deformation or veining. Decarbonation involved subjecting a $\sim 0.5 \mathrm{~g}$ aliquot of whole-rock powder to repeat 24 -hour, $10 \%$ (vol/vol) $\mathrm{HCl}$ leaches. Sample residues were then washed until $\mathrm{pH}$ neutral using Type 1 ultrapure (18.2 $\mathrm{M} \Omega \bullet \mathrm{cm}$ ) water and dried at below $40^{\circ} \mathrm{C}$. Carbonate content was then calculated gravimetrically from the dry sample residues.

The carbon isotopic composition of organic carbon $\left(\delta^{13} \mathrm{C}_{\mathrm{org}}\right)$ was measured in the GAPP Lab at Syracuse University using an Elementar Isotope Cube EA coupled to an Isoprime 100 IRMS. Decarbonated sample powders were loaded into tin capsules, evacuated, and purged with argon prior to analysis. The EA operating conditions were as follows: a helium purge was set for 45 seconds, the oxidation and reduction reactor temperatures were set at $1100^{\circ} \mathrm{C}$ and $650^{\circ} \mathrm{C}$, respectively; helium carrier gas flows were $230 \mathrm{ml} \mathrm{min}^{-1}$; the $\mathrm{O}_{2}$ pulse was set for 60 seconds and the $\mathrm{CO}_{2}$ trap was heated to $230^{\circ} \mathrm{C}$. Samples were run co-mingled with international reference materials ANU sucrose [+10.4\%o] and NIST 1547 peach leaves [-26.0\%o]. Sample and standard data were corrected to accepted values for the reference materials using the correction scheme described in Coplen et $a .^{38}$. Reproducibility for replicate samples and standards was better than $0.10 \%$ o $(1 \sigma)$.

Kerogen was extracted in the Geobiology laboratory at the University of St Andrews, following methods outlined in Zerkle et al. ${ }^{6}$. Approximately $100-200 \mathrm{mg}$ aliquots of bulk rock powder were decarbonated twice with $10 \%$ (vol/vol) $\mathrm{HCl}$ overnight at $40{ }^{\circ} \mathrm{C}$ in a clean hood. After being transferred to Teflon beakers in a dedicated fume cupboard, $5 \mathrm{ml}$ of $10 \% \mathrm{HCl}$ and 
$2 \mathrm{ml}$ of concentrated HF per $100 \mathrm{mg}$ powder were added and the samples heated to $35-40^{\circ} \mathrm{C}$. This procedure was performed twice on consecutive days, followed by an additional digestion in $10 \% \mathrm{HCl}$ to remove any residual Ca-fluorides. Once at incipient dryness the now silicatefree residues were rinsed five times with ultra-pure $(18.2 \mathrm{M} \Omega \bullet \mathrm{cm})$ water. Chloroform was added to the residue, shaken, and allowed to settle in separation funnels for about $30 \mathrm{~min}$. Heavy minerals that sank to the bottom were first removed, before the floating kerogen was transferred to another Teflon beaker and dried in a clean hood. Kerogen isolates were stored in an anaerobic chamber prior to analysis. For this study we performed only one kerogen extraction per sample, preventing reproducibility estimation for this step directly from these samples. However, previous comparison of kerogen extracted using our laboratory methods with a set of commercially extracted repeats yielded sub-1\%o inter-laboratory $\delta^{15} \mathrm{~N}_{\text {org }}$ variability $^{20}$.

Nitrogen isotope analyses of kerogens $\left(\delta^{15} \mathrm{~N}_{\mathrm{org}}\right)$ and decarbonated rock powders $\left(\delta^{15} \mathrm{~N}_{\text {bulk }}\right)$ were performed at the Syracuse University GAPP Lab using an automated 'nanoEA' system similar to that described in Polissar et al. ${ }^{39}$. The GAPP Lab nanoEA comprises an Elementar Isotope Cube EA coupled to an Isoprime Trace Gas analyser. The Trace Gas is used for $\mathrm{N}_{2}$ trapping and chromatographic focusing prior to sample gas introduction into the Isoprime 100 stable isotope mass spectrometer. Samples were loaded into tin capsules, evacuated, and purged with argon prior to introduction into the EA to remove interstitial atmospheric $\mathrm{N}_{2}$. The EA conditions were as follows: the helium purge was set for 45 seconds; the oxidation and reduction reactor temperatures were $1100^{\circ} \mathrm{C}$ and $650^{\circ} \mathrm{C}$, respectively; the helium carrier gas flow was $150 \mathrm{ml} \mathrm{min}^{-1}$; and the $\mathrm{O}_{2}$ pulse was set for 90 seconds. During sample analysis the full flow of the EA is diverted to an automated silica gel-filled cryotrap that is immersed in liquid nitrogen while $\mathrm{N}_{2}$ gas was being generated during combustion. The $\mathrm{N}_{2}$ trap is switched to a low-flow He carrier gas $\left(2 \mathrm{ml} \mathrm{min}^{-1}\right)$ via an automated Vici 6-port 
Valco valve and released to the IRMS through an Agilent CarboBond column $(25 \mathrm{~m} \times .53 \mathrm{~mm}$ x 5um).

Samples were run in triplicate on the NanoEA system using sequentially larger samples (i.e., 1, 2 and $3 \mathrm{mg}$ ) and blank corrected using Keeling-style plots. International reference materials IAEA N1 ammonium sulphate [0.4\%o]; $\mathrm{N}_{2}$ ammonium sulphate [20.3\%o]; NIST 1547 peach leaves [2.0\%o]; and in-house Messel Oil Shale [7.0\%o] were run in a similar manner, and in quantities of $\mathrm{N}$ that bracketed the $\mathrm{N}$-content of the sample materials. The resulting blank corrected samples and standard data were corrected to accepted values for the reference materials using the correction scheme described in Coplen et al. ${ }^{19}$. Reproducibility for replicate samples and standards using the nanoEA is $0.25 \%$, and approaches the reported nitrogen isotopic composition of the reference materials $(0.2 \%)$.

The nitrogen contents of kerogen (kerogen $\% \mathrm{~N}$ ) and bulk samples $(\mathrm{TN})$ were also determined using nano-EA IRMS total peak area data via blank subtraction and peak area response factors ( $\mu \mathrm{g}$ of $\mathrm{N}^{*}$ peak-area- $\mathrm{N}^{-1}$ ). The response factor was determined using replicates of NIST-1547 peach leaves (2.98 wt. \% N) distributed throughout sample analysis runs and bracketing the quantity of $\mathrm{N}$ found in the samples. Reproducibility of the $\mathrm{N}$ content of NIST-1547 peach leaves is $0.5 \%$ (relative error) and $+/-0.11$ wt. $\%(1 \sigma)$.

\section{Data Availability}

The authors declare that all data supporting the findings of this study are available within the article and its supplementary information files.

\section{References from Online Methods}

32 Izon, G. et al. Biological regulation of atmospheric chemistry en route to planetary oxygenation. Proceedings of the National Academy of Sciences 114, 2571-2579 (2017). 
33 Canfield, D. E., Raiswell, R., Westrich, J. T., Reaves, C. M. \& Berner, R. A. The use of chromium reduction in the analysis of reduced inorganic sulfur in sediments and shales. Chemical Geology 54, 149-155 (1986).

34 Mettam, C. et al. High-frequency fluctuations in redox conditions during the latest Permian mass extinction. Palaeogeography Palaeoclimatology Palaeoecology 485, 210-223 (2017).

35 Clarkson, M. O., Poulton, S. W., Guilbaud, R. \& Wood, R. A. Assessing the utility of $\mathrm{Fe} / \mathrm{Al}$ and the Fe-speciation to record water column redox conditions in carbonaterich sediments. Chemical Geology 382, 111-122 (2014).

36 Slotznick, S. P., Eiler, J. M. \& Fischer, W. W. The effect of metamorphism on iron mineralogy and the iron speciation redox proxy. Geochimica et Cosmochimica Acta 224, 96-115 (2018).

37 Grassineau, N. V. High-precision EA-IRMS analysis of S and C isotopes in geological materials. Frontiers in Analytical Chemistry - Applied Geochemistry 21, 756-765 (2006).

38 Coplen, T. B. et al. New guidelines for delta C-13 measurements. Analytical Chemistry 78, 2439-2441, doi:10.1021/ac052027c (2006).

39 Polissar, P. J., Fulton, J. M., Junium, C. K., Turich, C. H. \& Freeman, K. H. Measurement of ${ }^{13} \mathrm{C}$ and ${ }^{15} \mathrm{~N}$ isotopic composition on nanomolar quantitites of $\mathrm{C}$ and N. Analytical Chemistry 81, 755-763 (2009). 